\title{
COVID-19 PANDEMIJOS POVEIKIS SERGANČIŲJŲ MELANOMA HOSPITALINIAM PRIEINAMUMUI: PATIRTIS
}

\author{
Henrieta Janušonytė ${ }^{1}$, Vinsas Janušonis ${ }^{2,3}$, Gaivilè Kasap ${ }^{2,3}$ \\ ${ }^{1}$ Vilniaus universiteto Medicinos fakultetas, ${ }^{2}$ Klaipédos universitetine ligonine, \\ ${ }^{3}$ Klaipedos universitetas
}

\begin{abstract}
Raktažodžiai: melanoma, COVID-19 pandemija, onkologinès pagalbos prieinamumas.

\section{Santrauka}

COVID-19 pandemija sutrikdè ir apribojo visą sveikatos priežiūrą, ypač planinę, tarp jos onkologinę pagalbą, o kartu ir pagalbą sergantiems melanoma.

Darbo tikslas - ištirti ir palyginti pacientų, sergančiu melanoma, stacionarinès medicinos pagalbos prieinamumą iki COVID-19 pandemijos (2019) ir pandemijos (2020) metais.

Analizuotos įvairių šalių autorių mokslinės publikacijos nagrinejama tema, tirtos melanoma sirgusių pacientu ligos istorijos. Straipsnyje atskleisti pacientų, sirgusių melanoma ir hospitalizuotu abiem tirtais periodais, sveikatos priežiūros prieinamumo skirtumai ir priežastys. Nustatyta, kad sergančiųjų melanoma hospitalinis prieinamumas pandemijos metais buvo kiek sutrikęs, tačiau reikiama medicinos pagalba, tarp jos ir planinè, buvo teikiama.
\end{abstract}

\section{Ivadas}

COVID-19 pandemijos, dèl jos paskelbtos ekstremaliosios situacijos ir karantino metu buvo sutrikdyta visa sveikatos priežiūra, ypač planinè, o kartu ir onkologinių ligų diagnostikos bei gydymo procesas [1,2]. Buvo ribojama odos ligų, tarp jų ir melanomos, ambulatorinių vizitų bei hospitalizacijos galimybè, atidedamas operacinis gydymas $[3,4,5]$. Laiku nesuteikta medicinos pagalba pirminès melanomos atveju sudaro prielaidas jai plisti, metastazuoti, o metastatiné melanoma mažina išgyvenamumo galimybes [6]. Odos navikais, tarp jų melanoma sergančių pacientų skaičius pastaraji dešimtmeti augo, lygiagrečiai augant biopsijų skaičiui [7]. Vien JAV kasmet diagnozuojama apie 80 tūkst. naujų melanomos atvejų [8].

Biopsinès medžiagos paėmimas ir melanomos diagnozès patvirtinimas turi didelę reikšmę hospitaliniam prieinamu- mui. Palyginti su ikiepideminiais metais, COVID-19 pandemijos metu biopsijos paemimas ir melanomos patvirtinimas sutriko [9]. Pandemija paveikè visą, ypač planinę onkologinę sveikatos priežiūrą, ịskaitant sergančiuosius odos navikais, tarp jų ir melanoma $[10,11]$.

Pastebima, kad dažniau pavèluotai dèl melanomos kreipiasi vyrai, nei moterys [12]. Pavèluotai nustatyta melanomos diagnozè sunkina ligos eigą ir blogina baigtị $[13,14]$. Pandemijos metu melanoma buvo diagnozuojama ženkliai rečiau, todèl tikètina, kad tolesniais mènesiais ir metais melanoma bus toliau pažengusios stadijos ir sunkiau gydoma. Diagnozuoti melanomą ankstyvos stadijos ir kuo anksčiau nukreipti gydymui, kai reikia ir stacionariniam, pandemijos sąlygomis pirmiausia turi šeimos gydytojai [15].

COVID-19 pandemijos metu plačiai paplito nuotolinès konsultacijos, telemedicina odos ligų gydytojų praktikoje, tačiau kilus bent mažiausiam piktybinio naviko, ypač melanomos įtarimui, turi būti kontaktine dermatologo konsultacija dèl gydymo, jei reikia, stacionarinio ir operacinio [16,17].

COVID-19 pandemijos metu, sutrikus dermatovenerologinei pagalbai, atsirado didelè rizika, kad melanoma bus diagnozuota pavèluotai arba liks nediagnozuota [18], todèl COVID-19 pandemijos metu būtina pertvarkyti sergančiuju piktybiniais odos navikais sveikatos priežiūrą, tarp jų melanoma sergančių ir galimai sergančių pacientų $[8,19]$.

Melanoma daugiausia nustatoma vyresnio amžiaus žmonėms [22]. Melanoma sergančių pacientų mirštamumas COVID-19 pandemijos metu yra ženklus, todèl labai svarbus savalaikis operacinis ir kitas gydymas [20,21].

Daugèjantys užleistų odos navikų atvejai, didèjantis pacientų neigalumas ir mirtingumas didina sveikatos priežiūros kaštus [23], todèl COVID-19 pandemijos metu būtinas kompleksinis požiūris ị melanomos diagnostiką ir gydymą (kai reikia ir stacionare), kad liga nebūtų užleista, kelianti dideli pavojų pacientų sveikatai ir gyvybei.

Darbo tikslas - ištirti melanoma sergančių pacientų stacionarinès medicinos pagalbos prieinamumą iki COVID-19 pandemijos ir pandemijos metais. 


\section{Tyrimo objektas ir metodika}

Tyrimo objektas - stacionarinès medicinos pagalbos prieinamumas melanoma sergantiems pacientams Klaipédos universitetinèje ligoninèje.

Tyrimo medžiaga - Klaipèdos universitetinèje ligoninèje 2019-2020 dèl melanomos gydytų pacientų ligos istorijos.

Tyrimo metodai - literatūros analizè, klausimynas, statistine ir lyginamoji analizè.

Tyrimui atlikti naudotas autorių paruoštas specialus klausimynas (19 pozicijų su 50 galimų atsakymų).Tyrimas vykdytas $2021 \mathrm{~m}$. sausio - rugpjūčio mènesiais.

Analizuoti ir lyginti dviejų periodų tyrimo duomenys - 2019 m. (iki COVID-19 pandemijos pradžios) ir 2020 metų. Tyrimo duomenys analizuoti ir lyginti atsižvelgiant ic amžių, lytị, patekimo ị ligoninę būdą, geografinę sklaidą.

Iš viso tirtos 144 pacientų ligos istorijos: 83 gydyti $2019 \mathrm{~m}$. ir $61-2020$ metais. Moteru iš viso gydyta $78(54,2$ proc.): 2019 m. $-47(56,6$ proc.), 2020 m. -31 (50,8 proc.). Absoliuti dauguma pacientų $-118(81,9$ proc.) stacionare gydyti planine tvarka. Iš jų: $2019 \mathrm{~m}$. - 68 (81,9 proc.), 2020 m. - 50(81,9 proc.). Iš neplanine tvarka stacionare gydytų 26 pacientų: 24(92,3 proc.) atvyko patys, 2(7,7 proc.) pristate GMP.

Statistinè duomenų analizė atlikta naudojant statistinio duomenų analizès paketo IBM SPSS 23.0 versiją ir MS Excel 2016 programą. Duomenų skirtumas laikytinas statistiškai reikšmingu (SRS), kai $\mathrm{p}<0,05$ (statistinio pasikliautinumo lygmuo 95 proc.).

Tyrimo rezultatai ir jų aptarimas

Tirti pacientai pagal amžių: iki 50 $\mathrm{m}$. $-37(25,7$ proc.), $50 \mathrm{~m}$. ir daugiau - 107 (74,3 proc.). $2019 \mathrm{~m}$. moterų iki $50 \mathrm{~m}$. gydyta $19(40,4$ proc. visų gydytų moterų), 2020 m. -7 (22,6 proc. visu gydytų moteru). COVID-19 pandemijos metais kreipèsi ženkliai mažiau jaunų moterų (17,8 proc., SPS). 2019 m. gydyta vyrų iki $50 \mathrm{~m}$. 7(19,4 proc. visų gydytų vyrų), $2020 \mathrm{~m}$. -4 (13,3 proc. visų gydytų vyrų).

Daugumai melanomos diagnozė buvo nustatyta 1 ménesio laikotarpiu iki hospitalizacijos, statistiškai reikšmingo skirtumo lyginant 2019 ir 2020 m., ne-

1 lentelè. Laikas nuo melanomos diagnozès nustatymo iki hospitalizavimo. SNS - statistiškai nereikšmingas skirtumas.

\begin{tabular}{|c|c|c|c|c|c|c|}
\hline \multirow{3}{*}{ Laikas } & \multirow{2}{*}{\multicolumn{2}{|c|}{$\begin{array}{c}2019 \text { m. } \\
n_{1}=83\end{array}$}} & \multirow{2}{*}{\multicolumn{2}{|c|}{$\begin{array}{c}2020 \text { m. } \\
\mathrm{n}_{2}=61\end{array}$}} & \multirow{2}{*}{\multicolumn{2}{|c|}{$\frac{2019-2020}{n_{1}-n_{2}}$}} \\
\hline & & & & & & \\
\hline & abs.sk. & proc. & abs.sk. & proc. & skirt proc. & $\begin{array}{l}\text { statistinis skir- } \\
\text { tumo reikšmin- } \\
\text { gumas }\end{array}$ \\
\hline Iki 1 mèn. & 62 & 74,7 & 43 & 70,5 & 4,2 & SNS \\
\hline Nuo 1 mèn. iki 3 mėn. & 1 & 1,2 & 3 & 4,9 & $-3,7$ & SNS \\
\hline Nuo 3 mèn. iki 6 mèn. & 3 & 3,6 & 7 & 11,5 & $-7,9$ & SNS \\
\hline Nuo 6 mèn. iki 12 mèn. & 10 & 12,1 & 7 & 11,5 & 0,6 & SNS \\
\hline$>12$ mèn. & 7 & 8,4 & 1 & 1,6 & $-6,8$ & SNS \\
\hline
\end{tabular}

2 lentelè. Melanomos gydymo stacionare trukmè.

SNS - statistiškai nereikšmingas skirtumas.

\begin{tabular}{|l|c|c|c|c|c|c|}
\hline \multirow{2}{*}{ Metai } & \multicolumn{2}{|c|}{$\mathbf{2 0 1 9}$ m. } & \multicolumn{2}{c|}{2020 m. } & \multicolumn{2}{c|}{ 2019-2020 m. } \\
\cline { 2 - 7 } & \multicolumn{2}{|c|}{$\mathrm{n}_{1}=83$} & \multicolumn{2}{c|}{$\mathrm{n}_{2}=61$} & \multicolumn{2}{c|}{$\mathrm{n}_{1}-\mathrm{n}_{2}$} \\
\cline { 2 - 7 } & abs.sk. & proc. & abs.sk. & proc. & $\begin{array}{c}\text { skirtumas, } \\
\text { proc. }\end{array}$ & $\begin{array}{c}\text { statistinis skirtumo } \\
\text { reikšmingumas }\end{array}$ \\
\hline 1 diena & 45 & 54,2 & 34 & 55,7 & $-1,5$ & SNS \\
\hline 2 dienos & 8 & 9,6 & 1 & 1,6 & 8,0 & SNS \\
\hline 3 dienos & 3 & 3,6 & 2 & 3,3 & 0,3 & SNS \\
\hline 4 dienos & 1 & 1,2 & 1 & 1,6 & $-0,4$ & SNS \\
\hline 5 dienos & 0 & 0 & 0 & 0 & 0 & SNS \\
\hline$>5$ dienuc & 26 & 31,3 & 23 & 37,7 & $-6,4$ & SNS \\
\hline
\end{tabular}

3 lentelè. Melanomos lokalizacija.

SRS - statistiškai reikšmingas skirtumas; SNS - statistiškai nereikšmingas skirtumas.

\begin{tabular}{|l|c|c|c|c|c|c|}
\hline \multirow{2}{*}{ Metai } & \multicolumn{2}{|c|}{$\mathbf{2 0 1 9} \mathbf{~ m . ~}$} & \multicolumn{2}{c|}{$\mathbf{2 0 2 0} \mathbf{~ m . ~}$} & \multicolumn{2}{c|}{$\mathbf{2 0 1 9 - 2 0 2 0 ~ m . ~}$} \\
\cline { 2 - 7 } & \multicolumn{2}{|c|}{$\mathrm{n}_{1}=83$} & \multicolumn{2}{c|}{$\mathrm{n}_{2}=61$} & \multicolumn{2}{c|}{$\mathrm{n}_{1} \mathrm{n}_{2}$} \\
\cline { 2 - 7 } & abs.sk. & proc. & abs.sk. & proc. & proc. & $\begin{array}{c}\text { statistinis skirtumo } \\
\text { reikšmingumas }\end{array}$ \\
\hline Apatinès galūnès & 7 & 8,4 & 15 & 24,6 & $-16,2$ & SRS \\
\hline Viršutinès galūnès & 13 & 15,7 & 7 & 11,5 & 4,2 & SNS \\
\hline Galva & 17 & 20,5 & 13 & 21,3 & $-0,8$ & SNS \\
\hline Kūnas & 46 & 55,4 & 26 & 42,6 & 12,8 & SNS \\
\hline
\end{tabular}




\section{2}

buvo (1 lentelè).

Iš vèliau nei per 1 mèn. hospitalizuoto 21 paciento 2019 metais, 19(90,5 proc.) hospitalizuoti su jau anksčiau nustatyta melanomos diagnoze. $2020 \mathrm{~m}$. iš vèliau nei per 1 mèn. hospitalizuotų 18 pacientų, 17 (94,4 proc.) hospitalizuoti su jau anksčiau nustatyta melanomos diagnoze. Tai atitinka literatūros duomenis, kad COVID-19 pandemijos metais buvo sutrikdytas sergančiujų melanoma sveikatos priežiūros procesas [2-4].

Operuoti $102(70,8$ proc.) pacientai: $2019 \mathrm{~m} .56(67,5$ proc.) ir $2020 \mathrm{~m} .46(75,4$ proc.). COVID-19 pandemijos (2020) metais pacientų operuota santykinai daugiau, nei 2019 m. Iš 102 operuotų dèl melanomos pacientų, 73(71,6 proc.) taikyta bendrinè ar regioninè (spinalinè) nejautra, $29(28,4$ proc.) - vietinè. $2019 \mathrm{~m}$. bendra ar regioninè (spinalinè) nejautra taikyta 53(94,6 proc.) pacientams, $2020 \mathrm{~m}$. - 20(43,5 proc.). Nustatytas statistiškai reikšmingas skirtumas (SRS).

COVID-19 pandemijos (2020) metais vietiné nejautra taikyta daugiau nei du kartus dažniau, nei ikiepideminiais 2019 metais.

Dauguma operaciju - 76(74,5 proc.) buvo radikalios: 2019 m. 38(67,9 proc.) ir 2020 m. - 38 (82,6 proc.). COVID-19 pandemijos metais radikalių operacijų dalis buvo didesnè. Pooperacinių komplikacijų nebuvo (ligos istorijose apie jas nèra ịrašų). Biopsinè medžiaga paimta ir melanomos diagnozė histologiškai patvirtinta visais atvejais. Gydytojų konsiliumai dèl gydymo taktikos vyko (yra įrašai ligos istorijoje): $2019 \mathrm{~m}$. tartasi dèl 11 atvejų (19,6 proc.), $2020 \mathrm{~m}$. 44(95,7 proc.). Daliai pacientu $2019 \mathrm{~m}$. gydytojų konsiliumo dèl gydymo taktikos nereikejjo (kartotiniai pacientai ir kt.), nors tikètina, kad dalis konsiliumų ịvyko, tačiau jie neįrašyti ligos istorijose (konsiliumų registracijos žurnalai netikrinti).

Daugiau nei pusė pacientų (54,2 proc. 2019 m., 55,7 proc. 2020 m.) stacionare gydyti 1 dieną, daugiau kaip trečdalis ilgiau kaip 5 dienas (2 lentelè).

Statistiškai reikšmingo skirtumo tarp hospitalizacijos trukmès abiem nagrinetais periodais nebuvo. Melanomos lokalizacija dažniausia kūne: 2019 m. 55,4 proc. atvejų ir 2020 m. - 42,6 proc. atvejų. 2019 m. retesnè lokalizacija buvo apatinėse galūnèse, nei $2020 \mathrm{~m}$. (16,2 proc. mažiau) (3 lentelè).

2019 m. 41 (49,4 proc.) pacientas buvo hospitalizuotas esant jau nustatytai melanomos diagnozei (kreipèsi pakartotinai). $2020 \mathrm{~m}$. tokių pakartotinų atvejų buvo $23(37,7$ proc.). Ikipandeminiais $2019 \mathrm{~m}$. pakartotinai atvykusių ir hospitalizuotų pacientų buvo ženkliai daugiau ( 11,7 proc.), nei 2020 m. (SRS). Tai atitinka literatūros duomenis $[9,10,11]$.

Hospitalizuoti dèl melanomos pacientai pasirinko gydytoją $2019 \mathrm{~m}$. - 56(67,5 proc.), $2020 \mathrm{~m}$. - 28(45,9 proc.). Tiketina, kad COVID-19 pandemijos metais gydytojo pasirinkimas ligoninèje buvo ribotas dèl pandemijos, o ir pacientams gydytojo pasirinkimas buvo mažiau aktualus. COVID-19 liga sirgo 1 pacientas.

2019 m. visi pacientai išrašyti būklei pagerejjus, išskyrus 1 (1,2 proc.), mirusị dèl pagrindinès ligos - melanomos.

$2020 \mathrm{~m}$. visi pacientai išsirašè būklei pagerejus, išskyrus $4(6,6$ proc.) mirusius ( 3 - dèl pagrindinès ligos melanomos, 1 - dèl gretutinių ligų).

\section{Išvados}

Sergančiųų melanoma hospitalinis prieinamumas Klaipèdos universitetinèje ligoninèje pandeminiais 2020 metais buvo kiek pablogejęs, palyginus su ikipandeminiais 2019 metais dèl priežasčių, susijusių su epideminiais (karantinas) ribojimais.

\section{Literatūra}

1. Dinmohamed AG, Visser O, Verhoeven RHA, et al. Fewer cancer diagnoses during the Covid-19 epidemic in the Netherlands. The Lancet Oncology 2020; 21:750-751. https://doi.org/10.1016/S1470-2045(20)30265-5

2. Janušonis V. Sveikatos priežiūros ir tinkamumo pokyčiai karantino dèl Covid-19 epidemijos metu: pacientų nuomonè ir vertinimas (atvejo analizè). Sveikatos mokslai, 2020; 30:72-79. https://doi.org/10.35988/sm-hs.2020.181

3. Haar J, Hoes LR, Coles CE, et al. Caring for patients with cancer in the Covid-19 era. Nature Medicine 2020; 26:665-671. https://doi.org/10.1038/s41591-020-0874-8

4. Schrag D, Hershman DL, Basch E. Oncology practice during the Covid-19 pandemic. JAMA 2020; 232:2005-2006. https://doi.org/10.1001/jama.2020.6236

5. Radi G, Diotallevi F, Campanati A, Offidani A. Global coronavirus pandemic (2019-nCOV): implication for an Italian medium size dermatological clinic of ii level hospital. Journal of the European Academy of Dermatology and Venerology 2020. https://doi.org/10.1111/jdv.16386

6. Ueda M, Martins R, Hendrie PC, et al. Managing cancer care during the Covid-19 pandemic: agility and collaboration forward a common goal. Journal of the National Comprehensive Cancer Network 2020;18-366-369.

https://doi.org/10.6004/jnccn.2020.7560

7. Wang DM, Morgan FC, Besaw RJ, Schmults CD. An ecological study of skin biopsies and skin cancer treatment procedures in the United States Medicare population, 2000 to 2015. Journal of the American Academy of Dermatology 2018; 78:47-53. https://doi.org/10.1016/j.jaad.2017.09.031

8. Patrinely JR, Johnson DB. Pandemic medicine: the management of advanced melanoma during covid-19. Melanoma Management 2020 .

https://doi.org/10.2217/mmt-2020-0012

9. Asai Y, Nguyen P, Hanna TP. Impact of the Covid-19 pandemic 
on skin cancer diagnosis: a population - based study. PLOS ONE 2021.

https://doi.org/10.1371/journal.pone.0248492

10. Ricci F, Fania L, Paradisi A, et al. Delayed melanoma diagnosis in the Covid-19 era: increased breslow thickness in primary melanomas seen after the Covid-19 lockdown. Journal of the European Academy of Dermatology and Venerology 2020. https://doi.org/10.1111/jdv.16874

11. Gisondi P, Piaserico S, Conti A, Naldi L. Dermatologists and SARS-CoV-2: the impact of the pandemic on daily practice. Journal of the European Academy of Dermatology and Venerology 2020;34:1196-1201. https://doi.org/10.1111/jdv.16515

12. Mavor ME, Richardson H, Miao Q, et al. Disparities in diagnosis of advanced melanoma: a population-based cohort study. CMAJ Open 2018; 6:e502-e512. https://doi.org/10.9778/cmajo.20180089

13. Liu W, Dowling JP, Murray WK, et al. Rate of growth in melanomas: characteristics and associations of rapidly growing melanomas. Archives of Dermatology 2016;142:1551-1558. https://doi.org/10.1001/archderm.142.12.1551

14. Neal RD, Tharmanathan P, France B, et al. Is increased time to diagnosis and treatment in symptomatic cancer associated with poorer outcomes? Systematic review. British Journal of Cancer 2015; 112 Suppl 1: S92-S107.

https://doi.org/10.1038/bjc.2015.48

15. Conforti C, Giuffrida R, DiMeo N, Zalandek J. Management of advanced melanoma in the covid-19 era. Dermatologic Therapy 2020; 33:e1344. https://doi.org/10.1111/dth.13444

16. Conforti C, Giuffrida R, Verroni R, et al. Dermoscopy and the experienced clinicians. International Journal of Dermatology 2020; 59:16-22. https://doi.org/10.1111/ijd.14512

17. Rich H, Jones B, Malin I, et al. Plastic surgical management of skin cancer patients during the Covid-19 pandemic. Journal of Plastic, Reconstructive and Aesthetic Surgery 2020. https://doi.org/10.1016/j.bjps.2020.08.143

18. Conforti C, Lallas A, Argenziano G, et al. Impact of the covid-19 pandemic on dermatology practice worldwide: results of a survey promoted by the international dermoscopy society (IDS). Dermatology Practical and Conceptual 2021; 11:20211153. https://doi.org/10.5826/dpc.1101a153

19. Wolina U. Challenges of Covid-19 pandemic for dermatology. Dermatologic Therapy 2020. https://doi.org/10.1111/dth.13430

20. Friebel TR, Rinkoff S, Jemec B. Communication: a safe skin cancer surgery set up during the covid-19 crisis. Journal of Plastic, Reconstructive and Aesthetic Surgery 2021;74:644-710. https://doi.org/10.1016/j.bjps.2020.10.044

21. Andrew TW, Alrawi M, Lovat P. Reduction in skin cancer diagnoses in the UK during the Covid-19 pandemic. Clinical and Experimental Dermatology 2021;46:145-146.

https://doi.org/10.1111/ced.14411

22. Nehal RS, Bichakjian CK. Update on keratinocyte carcinomas. New England Journal of Medicine 2018;379:363-374. https://doi.org/10.1056/NEJMra1708701

23. Porcar SS, Pons BM, Guillen CS, Garcia VA. Attitudes of patients with skin tumors during the covid-19 pandemic. Actas Dermo-Sifiliograficas 2021;112:182-198. https://doi.org/10.1016/j.adengl.2020.12.023

\section{INFLUENCE OF COVID-19 PANDEMIC ON THE AVAILABILITY OF IN PATIENT ONCOLOGY CARE WITH MELANOMA}

H. Janušonytė, V. Janušonis, G. Kasap

Keywords: Melanoma, Covid-19 pandemic, availability of oncology care.

Summary

The Covid-19 pandemic disrupted and limited all health care, especially planned care, including oncology care and care for patients with melanoma.

The aim of this article - to study and compare the availability of impatient healthcare for patients with melanoma before and during Covid-19 pandemic.

Material and methods. From July to August 2021 the survey has been performed. The study used the medical histories of 144 patients with melanoma, treated in 2019-2020. The research data were analyzed and compared in two periods - 2019 and 2020 by age, gender, method of hospitalization, etc.

Analysis of statistical date was done using software SPSS version 23.

Results. Majority of patients treated in hospital were over 50 years $(74.3 \%)$, female $(54,2 \%)$, hospitalized on a scheduled basis $(81.8 \%)$ in both analyzed periods.

About three quarters of patients were hospitalized within one month of being diagnosed with melanoma. 70,8 percent of hospitalized patients underwent surgery, the diagnosis all patients was verified histologically.

Multidisciplinary councils on treatment tactics in 2020 took place four times more often than in 2019.

More than half of melanoma (51.4\%) are localized to the body. 55.6 percent of treated patients with melanoma diagnosis was made for the first time. $3.5 \%$ treated patients with melanoma died, others discharged from the hospital after recovery or recovery.

Conclusions. Hospital availability of patients with melanoma in Klaipeda university hospital in the epidemic 2020 was slightly worse then in the pre-epidemic year 2019 due to epidemic (quarantine) restrictions.

Correspondence to: janusonis@kul.1t

Gauta 2021-10-01 